\title{
Las fiestas patronales municipales: un aporte a la preservación de nuestra cultura tradicional chocoana
}

\section{Local traditional festival: Preserving and supporting the traditional culture of Chocó}

\section{Luz América Lozano Mayo*}

\section{Resumen}

Con el objeto de evaluar la relación entre la existencia de las fiestas patronales de los pueblos negros y la preservación de su cultura tradicional, se seleccionaron dos de ellas, San Francisco de Asís (San Pacho) en el municipio de Quibdó y Las Mercedes en Istmina; en cada una se realizó una búsqueda de información a través de observación directa aplicada durante el desarrollo de las mismas. Se tomaron notas de campo, registros fotográficos y de video para su análisis posterior. Además, se realizaron entrevistas estructuradas con cultores de la zona y se revisaron los diseños, las guías o programaciones de cada evento, lo que posibilitó conocer con anterioridad las actividades previstas y determinar así los focos de observación para obtener datos organizados y completos. En estos programas y plegables recopilados, se revisaron los objetivos contenidos de los eventos, a quienes se dedicaban las actividades y los espacios a presentar. Se elaboraron actas de evaluación que brindaron información que permitió corroborar el criterio de los especialistas y los datos obtenidos en la observación. Adicionalmente se investigó sobre la historia de la fiesta, su origen y se analizaron las declaraciones de los expertos entrevistados y los criterios de la población que junto con las reflexiones de la investigadora, permitieron evaluar el valor de las Fiestas Patronales como una herramienta que ha permitido conservar la tradición del territorio. La cultura nace con el hombre y los hombres se obligan a sus procesos culturales; en estos procesos se involucran los pensamientos de todo género para establecer la sostenibilidad social de todo el pensamiento humano. Las festividades san franciscano en Quibdó y mercedario en Istmina, conjugan el pensamiento tradicional de procesos históricos que se entrelazan con las tradiciones de un pasado que en el recordatorio del ayer con sus festividades se quiere hacer evidente hoy.

Palabras clave: Fiestas patronales, Cultura tradicional, Chocó, Conservación de la cultura.

\begin{abstract}
With the purpose of evaluating the relationship between traditional festivals of black communities and the preservation of its traditional culture there were selected two festivals: San Francisco De Asis (San Pacho) in the municipality of Quibdó and Las Mercedes in Istmina; in each search was performed information through direct observation applied during the development of thereof. They took field notes, photographic, videos records for further information. In addition, structured interviews were conducted in the area and reviewed of the designed schedules of each event which made it possible to know
\end{abstract}

* Antropóloga, Investigadora principal componente sociocultural, Instituto de Investigaciones Ambientales del Pacífico (IIAP), Quibdó, Colombia. e-mail: alozano@iiap.org.co

Recibido: 18 de enero de 2012 Aceptado: 20 de marzo de 2012 
in advanced planned the activities and determine the focus for observation to obtained data complete and organized.In this program and collected brochures, there was reviewed the objectives and all the contents of the event who were engaged with the space and the activities to present. Evaluation records were provided which allowed corroborating the opinion of the experts and the data obtained in the observation. Moreover, it was investigated the history of the festivals, and its background and there was analyzed the statements of the interviewed experts and the criteria of the population along with the reflections of the investigator who made it possible to assess the value of the traditional festivals as a tool that has preserve the tradition of the territory. Culture is born with humans and humans force their cultural processes; these processes are involved with thoughts of all kind to establish the social sustainability of all human thoughts. San Francisco de Asis 'festivals in Quibdó and Mercedes in Istmina combine the traditional thoughts and historical processes that are intertwined with the tradition of a past that remains in the yesterday with their festivities today.

Keywords: Traditional festival, Traditional culture, Chocó, Preserving cultural.

\section{Introducción}

La cultura popular tradicional representa una de las vías que tienen los grupos humanos y los pueblos, regiones y países para rescatar su memoria, expresar su creatividad y contar su historia. Según Hart $(1986,77)$ «Lo que no tiene raíces en la historia y en la tradición, es superficial». Las fiestas patronales en el Chocó son el reflejo de la rica herencia cultural prehispánica, africana y asiática que a través del fervor religioso y festivo impuesto por el colonialismo español se implantó en el nuevo continente. Con las distintas festividades se palpan los sentimientos más profundos del pueblo chocoano mostrando el valor social que cada región le otorga.

Las fiestas patronales son un sostén de la estructura social y han contribuido a evitar la pérdida de identidad de los valores tradicionales y la desintegración de las familias y sus comunidades. En la organización participan todos los sectores populares, cada uno de ellos contribuye a la conformación de las juntas pro festejos y participan de manera general todos los miembros de la comunidad.

En el Chocó, al igual que en otros departamentos del país, se investiga sobre temas relacionados con la cultura popular tradicional y existen instituciones dedicadas a ello como el área cultural del Banco de la República, la casa de la cultura de Quibdó al igual que en los otros municipios, la Universidad Tecnológica del Chocó, la Fundación Universitaria
Claretiana, quienes realizan y publican estudios que refieren la necesidad de preservar las tradiciones culturales en defensa de los rasgos identitarios. De ahí que se estudie esta temática no como algo pasado u obsoleto, sino como eje integrador de los diversos valores culturales que conforman la regionalidad y la nacionalidad, que constituyen el hilo conductor para la reafirmación de la identidad cultural.

Esta identidad cultural se ha protegido a través de la preservación de cada una de sus tradiciones. Por ello, la celebración de las fiestas patronales en el Chocó, es un importante hecho cultural, a través del cual se vivencian tradiciones conservadas y renovadas aún con el transcurso de los años y los cambios sociales acontecidos en el departamento (Ayala 2009). El rescate de tradiciones que conforman la cultura chocoana a través de estos eventos, es una prioridad para la institucionalidad, para el departamento del Chocó, en tanto que tiene entre sus objetivos esenciales, conservar y promover diferentes expresiones de la cultura popular chocoana.

Las consideraciones anteriores, justifican la necesidad de la realización de este estudio sobre las tradiciones asociadas con estos eventos y su contribución a la preservación de la cultura tradicional de las comunidades del territorio. Se defiende la idea de que el trabajo que realizan los promotores culturales para conservar las tradiciones materiales y espirituales de las comunidades en los asentamientos rurales, así como el incentivo a la creatividad individual y colectiva para mantener estas costumbres en las nuevas generaciones, son aportes con los que las celebraciones de las fiestas patronales municipales del Chocó, contribuyen de manera permanente.

Área de estudio. Quibdó es la capital del departamento colombiano del Chocó y una población importante en la región del Pacífico colombiano. La ciudad está ubicada en una de las regiones más forestales de Colombia, cerca de grandes reservas ecológicas como el Parque Nacional Natural y una de las regiones con un gran número de reservas indígenas. Se encuentra a orillas del río Atrato, uno de los principales afluentes del país y una de las zonas con más alta pluviosidad del mundo.

Esta antigua ciudad colombiana fue fundada por primera vez con el nombre Citará gracias a fray Matías Abad en el año de 1648 , en terrenos que regalaron los indios por primera vez a la orden franciscana. Esta población fue incendiada en diversas ocasiones por los indios. En 1654 fue reconstruida por los jesuitas Pedro Cáceres y Francisco de Orta. Hacia 1690, Manuel Cañizales, colono antioqueño y minero de profesión, fundó una población en tierras de los caciques Guasebá y Quibdó. En el año 1702, aumentaron los pobladores y el colono español Francisco de Berro, le dio el carácter de población, mediante acta firmada por los vecinos, con el nombre de «San Francisco de Quibdó».

Quibdó proclamó su independencia el 2 de febrero de 1813 
y por decreto ejecutivo del 30 de marzo de 1825 , se creó como cabecera de distrito. Con la creación del departamento del Chocó el 15 de junio de 1948, Quibdó se convirtió en su capital departamental. En 1966, la ciudad fue semidestruida por un incendio y nuevamente reconstruida por sus habitantes (Gonzáles2003).

Istmina. Istmina es un municipio de Colombia ubicado en el departamento de Chocó, fundado en 1834 por el señor Juan Nepomuceno Mosquera, inicialmente con el nombre de San Pablo, el cual fue cambiado en 1903 por el nombre actual. Su extensión es de $2480 \mathrm{~km}^{2}$ y cuenta con una temperatura promedio de $25.9^{\circ} \mathrm{C}$. Se encuentra a $75 \mathrm{~km}$ de Quibdó y a $79 \mathrm{msnm}$. La palabra Istmina se forma de la contracción de las palabras Istmo y Mina, dos características del área en el cual fue fundada. Es Nuestra Señora de las Mercedes patrona de Istmina y en honor a la fe que se le tiene, aparece en el escudo de esta localidad y en el cuadro de la derecha van los implementos utilizados para la minería como batea, almocafre y barra; en la parte inferior del mismo cuadro va la raíz de un árbol cortado, con el hacha incrustada, símbolo de la agricultura de la que junto con la minería derivan el sustento sus habitantes. En la parte inferior del óvalo ostenta un paisaje que resalta los cerros de la mojarra, altura máxima en la orografía del municipio; regando el valle aparece majestuoso el río San Juan, que recorre todo el municipio de norte a sur y su principal afluente, la quebrada San Pablo formando así la arteria fluvial de su hidrografía.

\section{Método}

Para evaluar la relación de las fiestas patronales de los pueblos negros con la preservación de la cultura tradicional del territorio, se seleccionaron dos fiestas patronales San Francisco de Asís (San Pacho) en el municipio de Quibdó y Las Mercedes en Istmina; en cada una se realizó una búsqueda de información precisa y exhaustiva. Para tal efecto se utilizó la observación participante abierta aplicada durante el desarrollo de dichas fiestas, lo cual fue esencial en la recolección de datos y para la descripción del contexto. Además, facilitó el estudio teniendo en cuenta que permitió el análisis directo de las actividades que se desarrollan, los comportamientos y conductas manifiestas por los participantes. Se tomaron notas de campo, registros fotográficos y de video para su análisis posterior.

También se realizaron entrevistas estructuradas con cultores de la zona y se revisaron los diseños, las guías o programaciones de los eventos, lo que posibilitó conocer con anterioridad las actividades previstas y determinar así los focos de observación para obtener datos organizados y completos. En dichos programas y plegables recopilados, se revisaron los objetivos contenidos de los eventos, a quienes se dedican las actividades y los espacios a presentar.

Se elaboraron actas de evaluación que brindaron información que permitió corroborar el criterio de los especialistas y los datos obtenidos en la observación. Adicionalmente

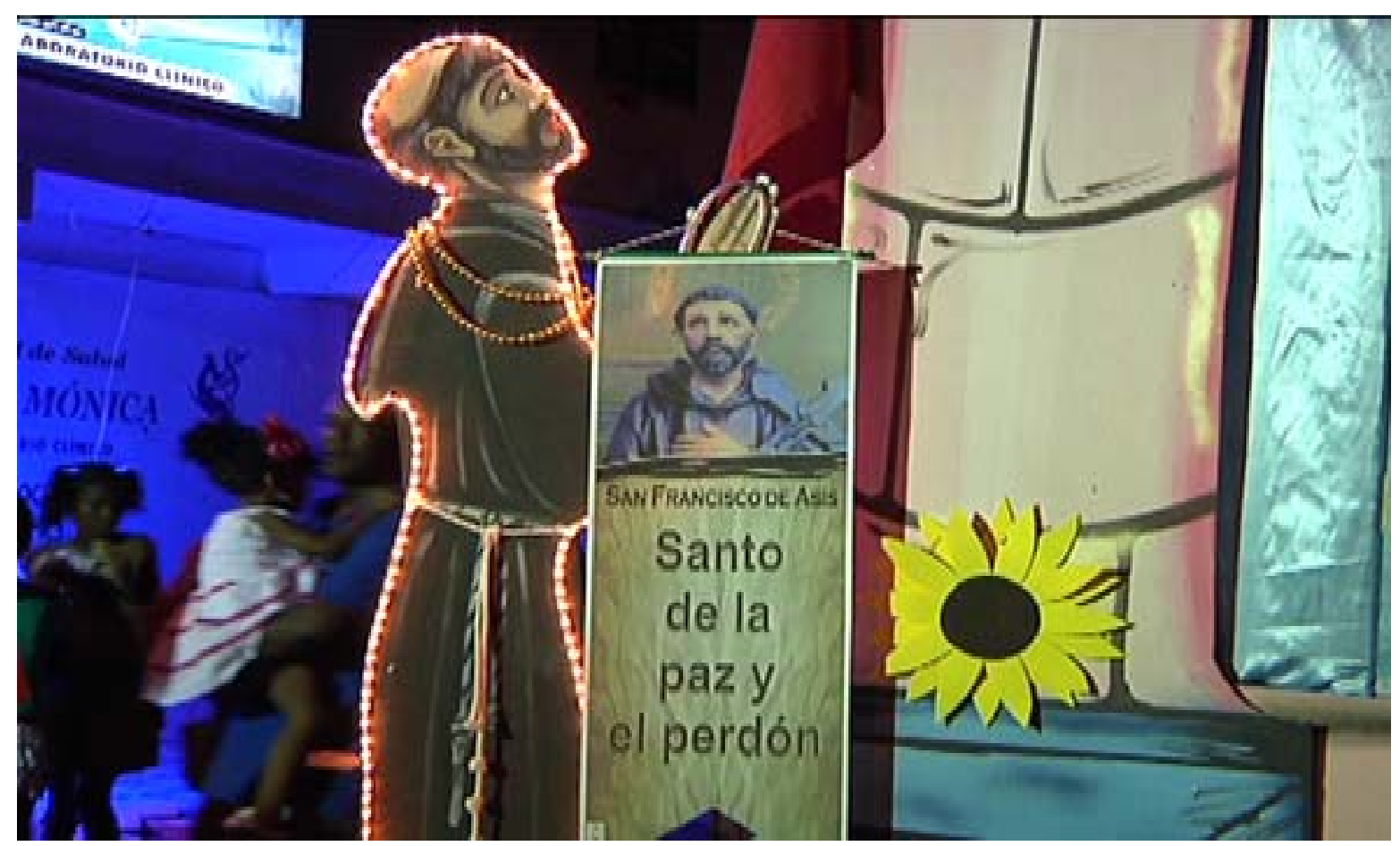

Figura 1. I magen de San Francisco de Asís 


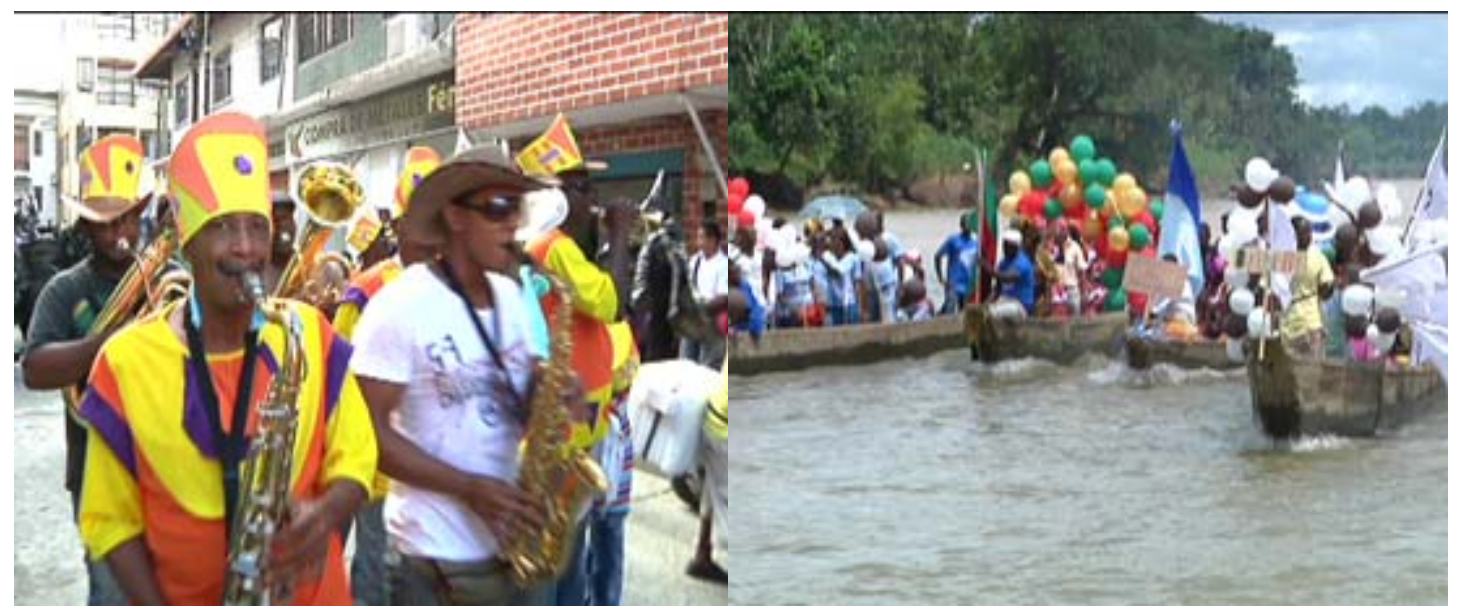

Figura 2. Chirima y balsadas. Fiesta patronal de San Pacho, Quibdó

se investigó sobre la historia de fiesta, su origen y se analizaron las declaraciones de los expertos entrevistados, los criterios de la población encuestada, que junto con las reflexiones de la investigadora, permitieron evaluar el valor de las Fiestas Patronales como una tradición del territorio.

\section{Resultados y discusión}

\section{Descripción de las fiestas patronales}

Las fiestas patronales de San Francisco de Asís. En los meses de septiembre y octubre en la ciudad de Quibdó a partir del siglo XX, cada año se celebran las festividades del santo patrono San Francisco de Asís (Figura 1), estas festividades se han convertido en uno de los referentes de importancia nacional que se muestra como estrategia cultural propia al carnaval y como elemento esencial de la cultura afrochocoana (La Tarde 2012). Es además, un vehículo a través del cual se afirma la identidad propia de la población afro como grupo con preponderancia demográfica y cultural en la ciudad. Los distintos elementos y los eventos que constituyen las fiestas, muestran la alternancia de expresiones en las que domina cierta religiosidad, no obstante que, de la misma manera se puede percibir las formas en las que domina las expresiones paganas. Esta práctica es fácil de observar en otras celebraciones a lo largo del Pacífico y la cual se constituye en elaboración sincrética en las que se integran las formas de vivenciar la religiosidad de las culturas africanas y las prácticas propias al modelo hispano (Friedemann 1989).

Las fiestas patronales comenzaron a efectuarse en Chocó desde la ocupación española. Siempre implicaban una alborada con chirimía, que anunciaban una fiesta, en donde se iban a presentar, misas, comparsas, disfraces, procesión, balsadas, actos culturales, verbena, vaca locas según fuera el caso (Ayala et al. 2009). Además de esta entre las más populares están las fiestas de Nuestra Señora del Rosario en Condoto, Nuestra Señora de la Candelaria en Certegui, Beté y Tagachí, Nuestra Señora de las Mercedes en Istmina, La Virgen del Carmen en Nuquí, Lloró, Bagadó, Managrú, Carmelo, La Ye, Acandí, ElCarmen de Atrato. De igual manera la Virgen de la Pobreza en Tadó y San Antonio en Yuto entre otros.

Las fiestas patronales tradicionales se desarrollan en el ambiente campestre chocoano y tienen plena vigencia porque han conseguido pervivir y conservarse a pesar de los diferentes cambios sociales. Se tipifican en bailes con chirimía, parrandas caseras, torneos o fiestas con equipos de sonido o de tambores (Figura 2).

La chirimia. El baile con chirimía en el Chocó es el festejo que se celebra en zonas tanto rurales como urbanas, en los que se empleaba la música campesina de marcada influencia hispánica. Años atrás contaban nuestros padres que estas festividades se celebraban con bailes de salón donde sobresalían el pasillo, el bolero, la danza y la contradanza, la polka, la mazurca y otros aires musicales que constituyen hitos históricos del acontecer social y cultural de esa época. Bailes realizados con instrumentos de cuerda como la lira, el tiple, la guitarra y el violín entre otros, instrumentos de viento como el cobre y el clarinete, donde se hicieron famosos músicos de reconocida trayectoria en la zona del San Juan tales como Antero Agualimpia, Teodoro Andrade, Rito Flórez, Lucio Torres, Antonio Asprilla, Esnel Torres, Aristarco Torres (oriundos de Condoto). Panadero, Iber Asprilla Mosquera, Albadigno Asprilla, Juan Eponuceno Mosquera, Toribio Mosquera, Raulin Aguilar, Wersale Aguilar (bateristas), Martin Cuesta, Telmo, Venito Cetre y Secundino Asprilla (nacidos en Istmina). Es importante anotar que la mayoría de estos ilustres y connotados músicos han fallecido, pero quedan aún sus vástagos quienes continúan en ese largo trasegar en la lucha por la sostenibilidad de estas expresiones de carácter cultural que identifican al 
departamento del Chocó.

Todas estas expresiones en sus momentos de soport estuvieron acompañadas de juegos de azar, del manejo del sortilegio, de juegos de cartas, dados, naipes, adivinaciones de la suerte, cantos y encantos para el amor, miradas del porvenir, venta de amuletos, de guardianes de la vida, preservación de enfermedades, de todo peligro y tantos imaginarios como la mente en momentos de estupor imaginativo produce en la alegoría festiva. Esta oportunidad es aprovechada por los distintos barrios o sectores poblacionales de cada municipio para realizar competencias, especialmente de carácter juvenil, en donde se destacan la carrera de encostalado, palo premios y danzas.

En estas fiestas cuya celebración se realizaba y se realiza hasta nuestros días, cada año, no podían faltar las gratas atenciones acompañadas de comidas típicas tales como arroz atollado, sancocho, guarrús, birimbí, arroz de maíz, el quebrado y el sancocho trascoldao (que entre otras cosas era el que provocaba los enamoramientos de parejas en cada baile), es decir que a pesar de las canciones, las cartas, serenatas y bebidas superfluas, contenían el famoso mancua, con supuestos poderes para la retención del enamoramiento masculino o femenino según fuera el caso.

Punto aparte merece señalar que los más prominentes productores de la agricultura preservaban sus mejores productos de sus distintas variedades para exponerlos y a la vez comercializarlos en las épocas festivas, generando así una competencia leal entre los más grandes cultivadores y productores de la agricultura regional. El consiente cultural del hombre chocoano no tiene otro espacio de mayor importancia que las festividades de sus pueblos para aprovechar quizás de manera incipiente sus propios recursos biodiversos que las circunstancias de sus festividades patronales, en las cuales no olvida una de sus mayores riquezas que es la capacidad hídrica que su posesión geográfica le ha permitido, y así en la muestra de su fe religiosa aprovecha la riqueza de sus indistintos ríos para pasear a sus santos devotos en los que cada pueblo en sus festividades incluye «balsadas» como un reconocimiento y bendición a esa grandiosa biodiversidad con que los ha dotado.

Es claro que las fiestas evolucionan y los cambios que se experimentan en el diario acontecer de la vida de los chocoanos, se proyectan igualmente en las festividades, lo cual precisa la identificación de estos. Pues el modo de vivir la religiosidad de las culturas afro, asume en ella la estructura de carnaval de otras regiones de América, New Orleans, de América Central, Río de Janeiro, siendo que su estructura se ordena con base en el modelo clásico del carnaval veneciano (Friedemann y Vanin 1991). La preservación de la cultura existe frente a las fiestas patronales de Quibdó e Istmina, mientras que la variación de las festividades está sujeta a los diferentes modelos con que las mismas comunidades hacen representaciones propias de sus formas de vida que en cada año imprimen y quieren mostrar los aconteceres de los acontecimientos de su existir relacionadas o dirigidas por sus patrones a quienes dedican sus esfuerzos con un sentido de veneración.

La comparsa. Las comparsas son alegorías, es decir son expresiones en donde el pueblo imita a la naturaleza y hace representaciones simbólicas de todo su ámbito social y cultural del pasado y el presente. En donde simboliza la riqueza natural y biodiversa, con la cual pretende imitar todos los aconteceres existenciales de su entorno. Con ellas se imitan personajes que sobresalen en distintas circunstancias que para bien o para mal generan impacto en el desarrollo de la vida cotidiana. Las comparsas son parte de la vida

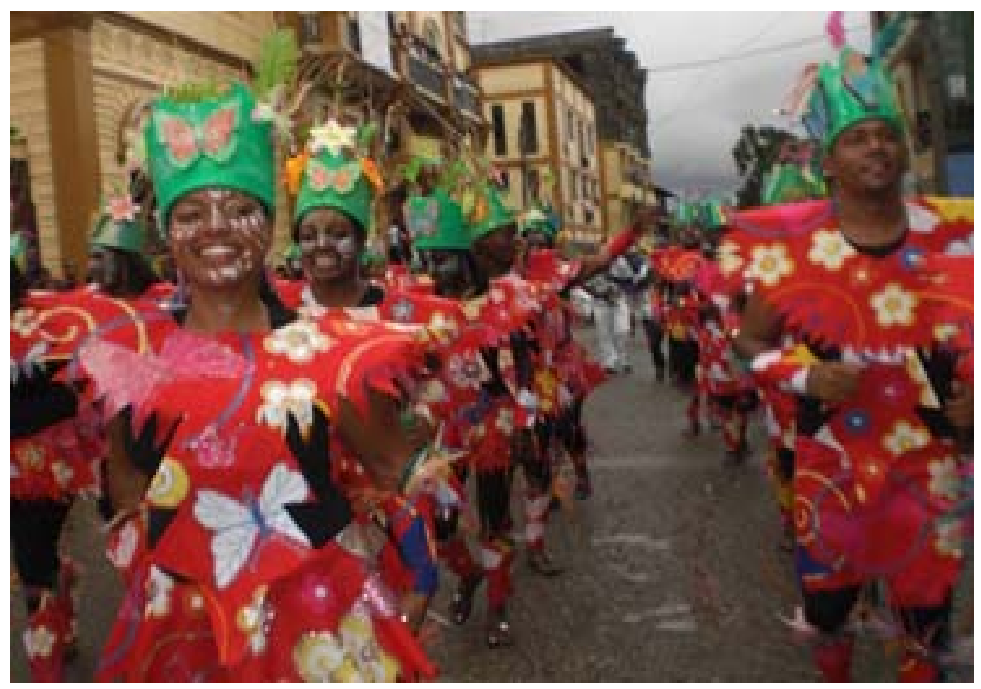

Figura 3. Comparsas. Fiestas Patronales de San Pacho, Quibdó 
fugaz de los pueblos y se constituyen en un espacio que convoca la participación indiscriminada de la sociedad, invitándola a participar en forma especialmente alegre, ya por la burla de sus representaciones, o por el acierto de sus manifestaciones. Es decir, esta es un espacio popular en donde el pueblo sin limitación alguna expresa de manera desbordante la alegría reprimida a través de manifestaciones simbólicas (Figura 3).

Una festividad que no presente comparsas en el Chocó, no tiene aceptación popular porque le estaría negando la participación amplia y abierta a toda su comunidad. Estas expresiones no tienen limitaciones de carácter social, político, económico, cultural, religioso etc. Pues lo pueblos más recónditos, para impactar a citadinos y visitantes, los cautiva con estas alegorías que en todas circunstancias expresan mensajes reales o ficticios de la vida de su comunidad.

Los disfraces. No existe en estas festividades una expresión más gráfica del acontecer social, cultural, político y económico que en forma crítica y alegre represente los acontecimientos históricos y actuales del desenvolvimiento de vida de estos pueblos (Villa 1989). Este es el espacio propicio en donde también se puede reconocer la capacidad inventiva del hombre chocoano que sin tener oportunidad en los medios públicos y su representatividad a través de los disfraces encuentra el medio más expedito para manifestar sus alegrías, tristezas, protestas y descontentos.

Los disfraces como en el más alto nivel del desarrollo europeo y del mundo cultural, la sociedad de estos pueblos se congrega para construir en forma representativa con los disfraces todas y cada una de las expresiones de las distintas circunstancias del acontecer de su vida histórica en el pasado y de su vida actual en el presente. Los disfraces en cada año se convierten igualmente en un recordatorio de la estructura social de estos pueblos, que en todo momento y en todo evento se congregan que a su vez van siendo modificadas con el acontecer de la sociedad mayoritarias para hacerle honor a sus patrones religiosos. Y es allí donde cambian y se modifica el pensamiento cultural y social de pueblos devotos que han signado su vocación a sus santos.

Encuentros sociales. En el ámbito de la fiesta también se realizan encuentros donde el pueblo se reúne para contar el origen del mundo, las proezas de líderes individuales y colectivos quienes fundaron sus pueblos y constituyeron amoríos para la dignidad y la grandeza de sus familias. Quienes con ligereza expresan la facilidad de conquista amorosa, encuentro en donde surgen los médicos tradicionales para efectuar el bien y el mal y en definitiva, donde se agiliza la compra y venta de un comercio cultural que culminada las festividades, debe reiniciar sus actividades de sostenibilidad en la fe de sus patronas y patrones en aras de alcanzar las soluciones que en derecho el Estado no les brinda. Eventos estos que ya no se realizan para dar paso a los nuevos aconteceres de la vida actual, como es el caso del establecimiento de reuniones de la juventud para imprimirle a las festividades la renovación generacional en donde se ponen en práctica nuevos ritmos musicales con los cuales se pretende desechar los bailes y la música tradicional, con la pretensión inconsciente que esta actitud forma parte de la renovación de las festividades patronales.

Las fiestas patronales la Virgen de las Mercedes en Istmina. El pueblo de Istmina que en su fundación se llamó inicialmente Istmo de Minas porque las riquezas de sus terrenos auríferos generó arduas disputas entre los distintos gambusinos por el empoderamiento de estas riquezas. El nombre del panteón de vírgenes, santos, ángeles y arcángeles, querubines, serafines, apóstoles y mártires que siendo desconocidos por los habitantes de la región, se les dejó como recordatorio histórico un patrón o patrona a los cuales debían rendirle honor y pleitesía en cada año de su existencia. De esta manera surgen las distintas festividades; estos hechos obligaron a los representantes de la fe católica para que hiciera la «mediación» entre los distintos confrontados para que zanjando sus disputas, tuviesen todos y cada uno merced del uno contra el otro, esta intervención del sacerdocio a través de una misa campal, permitió que esa el 24 de septiembre de la anualidad correspondiente se decretase las festividades de la Virgen de las Mercedes, festividad que albergó a todos los pueblos de la parte céntrica, media y baja del San Juan para constituirse capital apostólica de la provincia del San Juan.

Las festividades de la Mercedes en Istmina constituyen la expresión de más grande arraigo, de encuentro, de confraternidad, de alborozo y beneplácito no solo de los locales sino también de los citadinos, quienes con antelación apostan el encuentro de familias y familiares para hacer competencias de convivencias recorriendo los distintos barrios que compiten por ganar en cada año las mejores comparsa, los mejores disfraces, la mejor atención a sus visitantes, la mejor rumba y en definitiva el jolgorio de la mejor guacherna.

Estos eventos se muestran incluso rompiendo la institucionalidad del Estado colombiano cuando irrumpe uno de los barrios más populares que tiene por nombre Camellón de la República, el cual es uno de los más orgullosos de esta municipalidad porque en el recorrido de su parte alta que en su toponimia geoestratégica se encuentran dos cerros los de la Mojarra uno y los de la Mojarra dos, que es de donde se inician las valsadas con la imagen de la Virgen de las Mercedes, quien agraciada con todos los lujos y detalles impuestos por sus devotos, es paseada por el río San Juan hasta llegar al corregimiento de San Antonio (otro patrón regional).

En estas festividades se unen otros municipios y personas venidas del interior del país y se hace un verdadero derroche de las distintas expresiones culturales de carácter histórico y 


\section{Bioetnia Volumen 9 № 2 (julio-diciembre), 2012}

de la irrupción que las nuevas generaciones quieren imponer como moda. Y es aquí en donde el encuentro cultural de hombres y mujeres del ayer de jóvenes y niños muestran su creatividad en una competencia leal y digna con la cual quieren agradar a la patrona de su pueblo.

Aquí surge también la caracterología del pensamiento religioso y clerical, festividad a la cual son invitados de honor distintos hijos del sacerdocio y la congregación episcopal. Las festividades de la Virgen de las Mercedes no tienen un rigor de carácter regional sino de carácter nacional e internacional, pues a ella llegan hijos y visitantes que están ausentes y presentes dentro y por fuera del país colombiano. Porque el sentimiento de Mercedes para los istmineños no es solo de ellos sino de todos los seres humanos. Sin embargo Quibdó e Istmina representan unas de las fiestas patronales municipales: un aporte a la preservación de nuestra cultura tradicional chocoana, pueblos estos que gozan de una prevalencia histórica que es también la patrona de los reclusos no solo del Chocó sino de Colombia.

Los istmineños desarrollan variadas actividades que se constituyen en competencia barrial en la pretensión, de cada sector del poblamiento, de ganarse la bendición del aura de su patrona. Competencia esta que no solo en una de sus mayores expresiones que son las balsadas con que con adornos visten a su patrona, la pasean desde las riberas más altas del río San Juan, se muestra el orgullo, la dignidad y la verdadera vocación de los hijos de la Merced quienes después del jolgorio y el paseo y recorrido que por sus estrechas calles se hacen con la santa imagen, sus feligreses terminan bendiciendo su imagen y haciendo peticiones, ruegos y recordatorios y ayuda de todo género para mejorar las condiciones de vida.

\section{Aportes de las fiestas patronales municipales a la preservación de la cultura popular tradicional en el Chocó}

En términos generales se encontró que alrededor de las fiestas patronales de estudio se desarrollan actividades y situaciones específicas que favorecen la unidad y la conservación de las tradiciones:

Se programan para los niños, espacios con juegos tradicionales infantiles que propician no solo diversión con sus juegos cotidianos, sino también aprender. Los espacios de juegos tradicionales para adultos, propician diversión y permiten que se desarrollen juegos que se ejecutan de forma esporádica en las comunidades y son necesarios conservarlos, en tanto constituyen una tradición campesina.

- Los encuentros familiares son un espacio que contribuye a mantener vigentes en las nuevas generaciones; los mayores hacen remembranzas del ayer construyendo una nueva historia de los acontecimientos del presente.

Los espectáculos centrales y otras actividades que se desarrollan en los eventos, promueven el trabajo cultural que realiza el movimiento de artistas aficionados y los profesionales del territorio en función de preservar tradiciones campesinas. También propician la participación de narradores orales que cuentan historias relacionadas con sus comunidades o la manera de vivir de los campesinos y que han sido trasmitidas de una generación a otra. La celebración de las fiestas patronales, contribuye a preservar el repertorio de las danzas tradicionales que distingue la cultura popular tradicional en la parte urbana y la rural. Este evento difunde en los diferentes municipios, bailes autóctonos mencionarlos como con las características de los pueblos.

- Las danzas más representativas sin lugar a equivocaciones, los aportes realizados en materia de aires musicales por las comunidades afrodescendientes, superan, en número a las de cualquiera otra región de nuestro país. Según el doctor Abadía Morales, ello se debe a los siguientes factores como la gran afluencia del elemento africano traído en la colonia y cuya entrada al país se hizo principalmente por el río Atrato y la conservación con mínimo mulataje de los aportes de la comunidad negra ancestral, la supervivencia de cantos y danzas españolas que se enclavaron en la comunidad negra y se conservan hasta hoy con muy pocas modificaciones permitiendo la aportación de más de 26 aires musicales, anticipando como elemento básico y más representativo el currulao. La exposición de platos y bebidas expresa lo más representativo de la alimentación de cada comunidad, así como productos que cosechan y con los cuales elaboran sus platos. Se destaca fundamentalmente la presencia de la mujer, que compite por presentar el plato más representativo y original. Se presentan algunos de uso cotidiano, típicos u otros resultados de la creatividad de quienes los elaboran. Resultan usuales en todos los municipios los dulces elaborados con frutas en almíbar, turrones, galletas cucas, cocadas asadas y enyucados; pudines, derivados del maíz, masas, runchas, mazamorra, birinbi, arroz de maíz, el arroz entre los que se destacan arroz atollado, empedrado, arroz con longaniza, arroz con de todito, harina para panes, hojaldras y frituras. La presencia de bebidas es diversa en cada uno de los territorios, pero el café y la aguadepanela se encuentra en todos los municipios.

La exposición de artesanía, permite que se exhiba el trabajo artesanal desarrollado por los comunitarios exponentes de los géneros artesanales más tradicionales del territorio, los que presentan obras confeccionadas con técnicas como el cabecinegro, la damagua, la hiraca, el guerregue. Se realizan exposiciones de útiles de trabajo 
en el que los campesinos exhiben instrumentos que facilitan su producción y medios tradicionales de transporte. Constituye una generalidad encontrar una muestra de instrumentos de trabajo como bateas, canoas, palancas, canaletes, totumos, cucharas de mate, atarrayas entre otros.

La exposición de animales, frutas y vegetales, muestran a la población participante en el evento, lo más selecto de los logros productivos alcanzados por ellos, en tanto la cría de animales y el cultivo de la tierra, constituyen tradicionalmente, las principales fuentes de empleo en las zonas rurales. Los animales que se presentan en la mayoría de los municipios son cerdos, y gallinas criollas. Frutas y vegetales que se cosechan varían según el municipio, pero no faltan los plátanos, borojó, chontaduro, yuca, lulos, ajíes, maíz y ñame.

- Las exposiciones de útiles para el hogar muestran objetos de uso tradicional que se encuentran en viviendas rurales y otros que han disminuido su empleo, pero que se conservan y se utilizan en algunas ocasiones para las labores domésticas. Entre los útiles presentes en todos los municipios aparecen la batea y tabla para lavar, mazo, tabla para picar, rayos, mesas, sillas en madera, fogón de leña o carbón, el colador de café y el pilón.

Los datos obtenidos muestran que las fiestas patronales municipales se han convertido en el transcurso de los años, en eventos que integran niños, jóvenes y adultos. Actualmente constituyen actividades tradicionales y populares de mayor trascendencia en las comunidades urbanas y rurales del Chocó. Su celebración la espera cada año toda la población, pues no solo encuentran un espacio para el disfrute, además contribuyen a preservar las más genuinas expresiones de su cultura material y espiritual.

Las fiestas en el Chocó son el reflejo de la rica herencia cultural prehispánica y el fervor religioso impuesto por el colonialismo español. En ella se palpan los sentimientos más profundos del pueblo chocoano y el valor social que cada región le otorga. Una muestra de ello es que el Chocó después de largos años de vida de representatividad cultural que por múltiples razones ameritaba igual que otros países del mundo la más alta distinción y reconocimiento, de los más altos organismos de la cultura universal.

Por esta razón los organismos de carácter local, institucional, eclesiástico, departamental y nacional, que el departamento del Chocó en su buen entender encontró que la cultura regional ameritaba ser competitiva en el confrontamiento cultural de los pueblos en vía de desarrollo. Y es así como, el departamento del Chocó y su capital Quibdó con las festividades de San Francisco de Asís ha sido reconocida y aclamada a nivel nacional e internacional para otorgarle por la UNESCO el más alto título de reconocimiento cultural de los pueblos de dignidad y de orgullo universal que se recono- cen como Patrimonio Inmaterial de la Humanidad.

Colombia hace parte de un proceso normado y enmarcado por la Convención de Patrimonio Inmaterial de la Humanidad de la Unesco desde el año 2003 lugar donde se gestionan las peticiones de este tipo por parte de los estados. Esta festividad de origen africano, celebrada cada año desde el 3 de septiembre y hasta el 5 de octubre, tiene lugar en los doce barrios franciscanos de Quibdó, en el departamento del Chocó y está marcada por una religiosidad popular que comienza con una misa inaugural católica, y que se mezcla con las danzas tradicionales al son de la música de chirimía, seguido por desfiles carnavalescos con carrozas, disfraces y bailes, en honor al patrón de la localidad, San Francisco de Asís señaló Isaza a Colprensa.

Según expertos de la UNESCO, este reconocimiento se dio con el fin de «fortalecer la identidad del departamento y fomentar la cohesión social de la comunidad, propiciando al mismo tiempo la creatividad y la innovación, al revitalizar y recrear los conocimientos tradicionales y el respeto de la naturaleza». Las fiestas son un sostén de la estructura social y han contribuido a evitar la pérdida de identidad, de los valores tradicionales y la desintegración de toda la comunidad.

En la organización participan todos los sectores sociales, cada uno de ellos en el rol que le asignó la comunidad. El rol más significativo es el de las juntas pro festejos o encargados de la fiesta, cuyos roles pueden ser transitorios o permanentes, porque son elegidos específicamente para una celebración en particular o por largo tiempo, dependiendo de cada sitio. Están los «directores» de los grupos de danza y de las representaciones. Otros roles importantes son los encargados de la música, los que deben ocuparse de la pólvora y los que tienen la responsabilidad de elaborar las comidas tradicionales especiales para la ocasión.

Las fiestas tradicionales son las que se rigen por el calendario católico, aunque conserven aspectos de origen netamente prehispánicos. Esto se debe a que los valores religiosos cristianos fueron impuestos por la conquista a sangre y fuego. Como una manera de preservar sus costumbres religiosas, los indígenas hicieron su propia interpretación de la religión adaptándola a sus creencias ancestrales, provocando una síntesis muy particular. Hablar de las distintas festividades de carácter patronal en el departamento del Chocó, implica sustentar una deriva histórico-antropológica que se remonta a los orígenes mismos de la creación de todos y cada uno de los pueblos que hoy lo constituyen, iniciando por la presencia española en la conquista de sus territorios, pues con estos arribo igualmente no solo el pensamiento riesgoso y la voluntad bizarría que nunca segó el apetito glotón de la riqueza a través de la imposición y el sometimiento de una cultura extranjera a los suelos de América y con ellas al Chocó, sino que también, se impuso a los pueblos 


\section{Bioetnia Volumen 9 № 2 (julio-diciembre), 2012}

nativos la fe católica y apostólica en el fundamento de todos y cada uno de estos pobladores.

Es así como con el sometimiento y la explotación de los recursos, en cada sitio explotado se dejaba un santo y seña en nombre del panteón de vírgenes, santos, ángeles y arcángeles, querubines, serafines, apóstoles y mártires que siendo desconocidos por los habitantes de la región, se les dejo como recordatorio histórico un patrón o patrona a los cuales deben rendirle honor y pleitesía en cada año de su existencia. De esta manera surgen las distintas festividades con que el departamento del Chocó celebra anualmente sus fiestas patronales, depositando su fe, confianza y esperanza en un legado que sin ser su propia voluntad, se vio aferrado a creer en el de la nueva construcción de su historia social y cultural. No obstante es válido anotar que el influjo religioso no solo caló en los pueblos de América, sino también en muchos otros países que a pesar de tener culturas distintas y religiones diferentes, la creencia en seres superiores rebasó el pensamiento humano.

En el Chocó las conductas memorables tienen una vigencia especial significada en todos los pueblos y en todos los barrios; siempre se hace un recordatorio de los personajes del ayer y de los personajes de hoy. Estas relaciones son las que históricamente han sostenido las festividades de San Francisco de Asís en Quibdó y de las fiestas patronales de las Mercedes en Istmina, porque de puerta en puerta especialmente el género femenino en estos municipios impulsaron la creencia y la fe en estas festividades. Prueba de ello es que por ejemplo en Quibdó las festividades de San Francisco de Asís datan de 363 años ininterrumpidos en el festejo de su memoria. Con un pueblo como el de Istmina que con 175 años de adoración de la Virgen de las Mercedes muestran a la faz del mundo la abnegación de los feligreses de estos pueblos que de manera irredenta no han renunciado, no renuncian y en los historiales de su conducta religiosa, parece ser que no renunciaran tampoco a su fe religiosa y católica en la adoración de sus santos. Son muchos los años de existencia de estas fiestas. Un hecho fehaciente lo señalan algunas de las personalidades que logramos entrevistar:

Ana Gilma Ayala. «Las fiestas patronales se constituyen en la plataforma sociocultural, religiosa y económica de Quibdó y de todo el Chocó. La importancia de las fiesta radica en sus componentes de integración en las relaciones interétnicas que se dan en el marco de las fiestas puesto que nosotros no tenemos VIP, aquí todos disfrutamos no hay espacios cerrados, San Pacho es de todos y para todos. Como herencia social tradicional de nuestros mayores recobra una vital importancia porque la mayoría de las personas que hacen parte de las juntas barriales o de la fundación franciscana han tenido que ver con otras personas que en el pasado hicieron parte de las fiestas es decir es una especie de herencia social que viene en línea descendente, entonces desde ese punto de vista recobra mucha importancia. Hay un elemento nuevo y es que todas las fiestas patronales del Chocó están tomando la estructura organizativa de San Pacho y esto establece unas relaciones interculturales dentro del mismo Chocó. Es decir San Pacho permeó todas las fiestas patronales del Chocó. En las fiestas de San Pacho se dan dos componentes, el cultural y el religioso que se replican en los pueblos».

Dante Mosquera. «Este evento constituye un incentivo para todas aquellas personas que desarrollan su propia identidad y sus arraigos culturales. Las Fiestas Patronales que se celebran en todo el ámbito chocoano, responden específicamente a la posibilidad de réplicas del origen de múltiples imbridaciones culturales, que hoy asentadas en los dos litorales que tiene el departamento del Chocó, quizás por un indicativo mental y genético reproducen el dolor, la tristeza, pero también la alegría de la comunicación con sus ancestros. Por esta razón las fiestas patronales del pueblo chocoano se constituyen en el reencuentro más que el dominio y sometimiento, el mal recordatorio de tiempos y familias que quieren olvidar el más alto ultraje que se haya presentado en la especie humana como fue la esclavitud».

Maruja Uribe. «Las Fiestas Patronales representan la expresión cultural de un pueblo que va más allá de un espectáculo carnavalesco, en la medida que se unan el arte y la cultura se sienta un precedente con los disfraces y comparsas que viene a ser un vínculo entre lo pagano y lo religioso. Las Fiestas Patronales es una manifestación que involucra y rompe esquemas del individualismo y la propiedad, un sano desarrollo de las fiestas que identifican a un pueblo; podríamos decir que San Pacho es una de esas fiestas que concita a la unión a ella llegan no solo propios y extraños, sino de todas las regiones del Chocó, del país y del exterior por ser la máxima expresión cultural que rompe paradigmas, rompe esquemas».

Los hechos antes relacionados se constituyen en evidencia cierta y verdadera de que la cultura en el departamento del Chocó, no solo tiene arraigos en el ámbito formal de la religiosidad, sino también que está comprometida con el desenvolvimiento histórico de la conformación de sus pueblos partiendo del ámbito espiritual que es demostrado en el campo material (es decir de lo religioso a lo pagano. Por ejemplo en las festividades que se realizan en el departamento del Chocó, subsisten comportamientos culturales que denotan la proveniencia de raíces ancestrales que se enmarcan entre lo profano y lo religioso. Por esta razón las festividades, conductas y comportamientos de una diversidad de carácter cultural que aceptando el soporte de advenedizos, enriquecen más las festividades patronales en estas poblaciones del departamento del Chocó. 


\section{Conclusiones}

Si se puede establecer un reconocimiento histórico de la estructura social y cultural del pueblo colombiano es meritorio reconocer que en los poderes centrales existe una división de caracterología que establecen privilegios con base en distintas razones que no es meritorio mencionar en este proceso de investigación. Pero si es bueno señalar que el desarrollo cultural que han desplegado los negros en todo el ámbito geográfico del departamento del Chocó, con su pensamiento, con su idolatría y su religiosidad, construyeron y formaron parte en lo que hoy en día es la identidad de Colombia. Sin embargo en el Chocó se acentuó la más ferviente fe en San Francisco de Asís en Quibdó y en la Virgen de las Mercedes en Istmina depositarios estos creyentes construyeron también un ideario cultural de carácter religioso: Patrón y Patrona de sus pueblos, en los cuales creen fervientemente que los procesos culturales de todo su acontecer, estén amparados por ellos. Aquí esta pues reflejada el amparo de la vida política, social, cultural, económica y religiosa del hombre de la región.

\section{Literatura citada}

Ayala, A. 2009. Reseña histórica de la fiesta de San Francisco de Asís. Quibdó: Instituto de Investigaciones Ambientales del Pacífico. 102 pp.

Ayala, A., D. Cújar, J. Ramírez. 2009. Fechas y referentes de la fiesta franciscana. Quibdó: Ed. Mundo Libro. 89 pp.

Friedemann, N. 1989. Criele criele son. Del Pacífico negro. De cómo William Villa aprendió a mirar al santo. Bogotá: Editorial Planeta Colombiana. pp. 56-58.

Friedemann, N., A. Vanín. 1991. El Chocó, magia y leyenda. Bogotá: Litografía Arco. 132 pp.

González, L. 2003 Quibdó: Contexto histórico, desarrollo urbano y patrimonio arquitectónico. Medellín: Universidad Nacional de Colombia. 58 pp.

La Tarde. 2012. Fiestas de San Pacho en el Chocó, declaradas Patrimonio Inmaterial de la Humanidad. [en línea]. Consultado 5 diciembre de 2012: http://www.latarde.com/actualidad/colombia/105184-fiestas-desan-pacho-en-el-choco-declaradas-patrimonio-inmaterial-de-la-h

Villa, W. 1989. San Francisco de Asís o la poética de la calle. Boletín Cultural y Bibliográfico del Banco de la República. XXVI (19): 23-37. 